CRONICA UNIVERSITÁRIA.

\title{
Prof. Dr. Alfredo Buzaid - Diretor da Faculdade de Direito.
}

Prof. Dr. Alfredo Buzaid, diretor desta Faculdade. nasceu na cidade de Jaboticabal, Estado de S. Paulo, no dia 20 de julho de 1914. Fêz o curso primário e secundário no Ginásio São Luiz de Jaboticabal, dirigido pelo Prof. Aurélio Arrobas Martins, bacharelando-se no ano de 1930. Sua inclinação pelas letras despertou cêdo. Cursava o quarto ano do ginásio, quando entrou para o corpo de redação do jornal publicado pelo Centro Joaquim Nabuco. No quinto ano ginasial, encerrando o curso denominado de bacharelado, foi eleito orador oficial das três turmas de reservistas, respectivamente do Ginásio, da Escola de Farmácia e da Escola de Odontologia.

Ingressou na Faculdade de Direito de São Paulo em 1931. Prossegue sua atividade de jornalista, escrevendo especialmente para " $O$ Combate" de Jaboticabal e depois para "A Gazeta Comercial", da qual foi diretor. Concluído o curso acadêmico, advogou dois anos e meio em Jaboticabal, transferindo-se para São Paulo em fins de 1938. Desde então revelara seu interêsse pelos estudos de direito processual civil, publicando em 1939 um artigo sôbre Despacho Saneador na Revista Judiciária.

Quando Enrico Tullio Liebman iniciou seu curso de extensão universitária na Faculdade de Direito, foi Alfredo Buzaid um dos mais assíduos freqüentadores, tornando-se em pouco amigo pessoal do notável mestre italiano.

Em 1943 publicou seu primeiro livro - Da Ação Declaratória no Direito Brasileiro, com que se inicia a Coleção de Estudos de Direito Processual Civil, dirigida 
pelos professôres S. Soares de Faria e Enrico Tullio Liebman. Inscreve-se em 1945, com a monografia - Do Agravo de Petição no Sistema do Código de Processo Civil - no concurso à docência livre, tendo sido aprovado e nomeado no dia 17 de agôsto de 1946.

Publicou até 1951 os segúintes trabalhos: Da Apelação Ex Officio; Paula Batista (Atualidades de um velho processualista); e a Escola de Direito de Beirute. Em 1952 inscreve-se no concurso à cátedra de Direito Judiciário Civil na Faculdade Paulista de Direito da Pontíficia Universidade Católica de S. Paulo, apresentando a monografia denominada - Do Concurso de Credores no Processo da Execução. Venceu o concurso, obtendo a média 9.9. Foi nomeado e empossado no dia 23 de maio de 1953.

Publicou pareceres e artigos de doutrina na Revista dos Tribunais, na Revista Forense e na Revista Jurídica. Participou de Comissão Julgadora de concurso à cátedra de Direito Judiciário Civil nas Universidades de Belo Horizonte. Porto Algre e do Rio de Janeiro (Universidade do Brasil). Pertence à Associação Italiana de Processo Civil com sede em Florença e é membro do Instituto Ibero-Luso-Filipino e Americano de Processo Civil, com sede em Madrid. E conselheiro da Revista de Derecho Processal Civil, editada em Madrí; sob os auspícios do referido Instituto publicou ainda a monografia - Da Ação Direta de Declaração de Inconstitucionalidade no Direito Brasileiro.

Em 1957 inscreveu-se, na Faculdade de Direito da Universidade de São Paulo, no concurso à cátedra de Direito Judiciário Civil, vaga com o falecimento do Prof. Benedito de Siqueira Ferreira. Sua monografia denominou-se - Da Ação Renovatória de Contrato de Locação de Prédio Destinado a Fins Comerciais ou Industriais. Alcancou distinção em tôdas as provas e com todos os examinadores, tendo sido nomeado e empossado na cadeira no dia 8 de maio de 1958, em sessão solene da Congregação. 


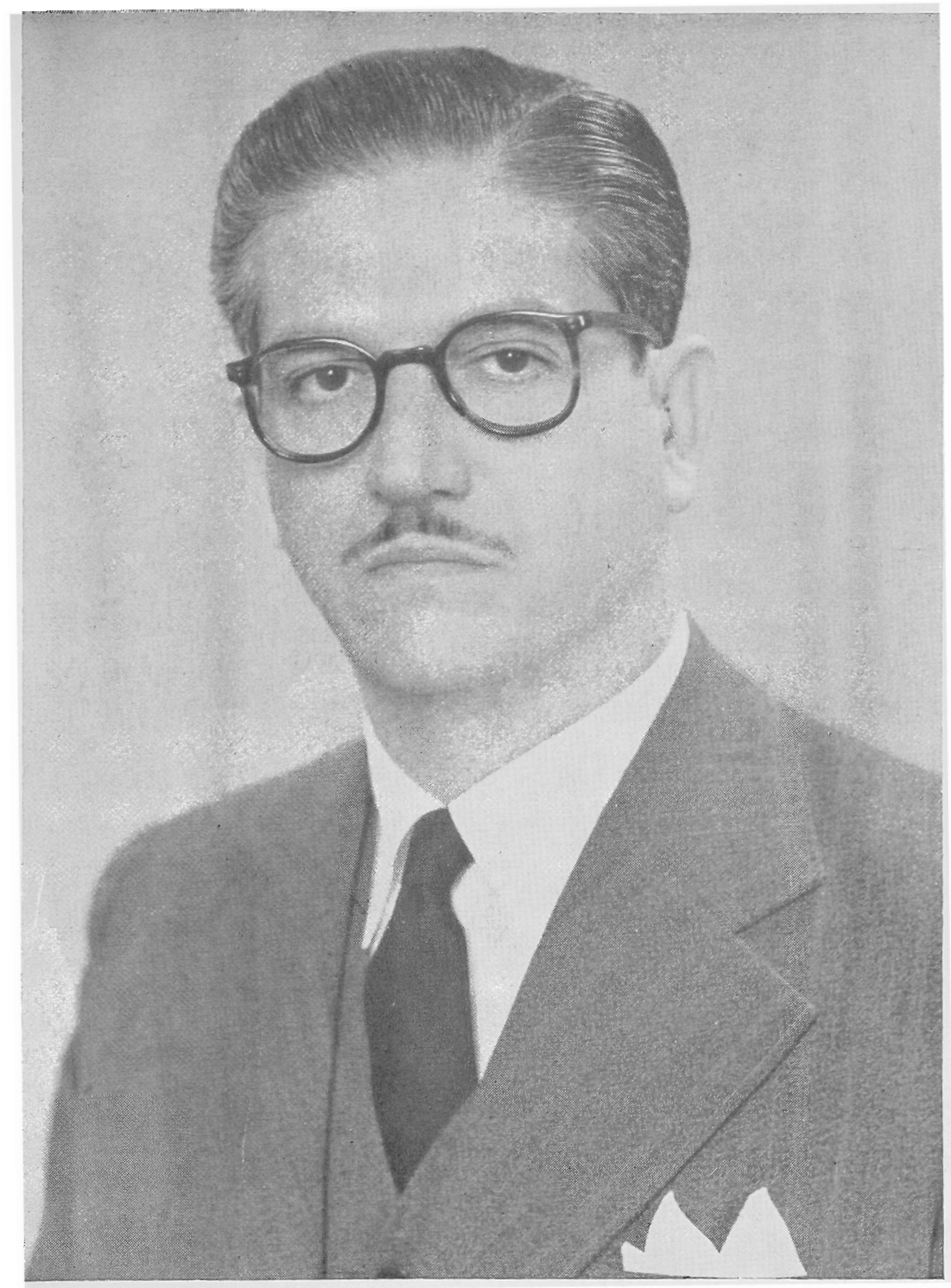

PROF. DR. ALFREDO BUZAID

Diretor da Faculdade de Direito, da Universidade de São Paulo 
Após a brilhante conquista da cátedra, S. Excia. continuou, sem esmorecimento, a dedicar-se ao ensino, à pesquisa e à advocacia.

Como Secretário Geral do Instituto Brasileiro de Direito Processual Civil, organizou, em 1962, nesta Faculdade, o primeiro Congresso Internacional de Direito Frocessual, ao qual compareceram renomados catedráticos da Europa e Américas, com profícuos resultados para a processualística.

Em janeiro de 1964, após intensivos meses de trabalho, apresentou ao Ministro da Justiça e Negócios Interiores o ante-projeto do Código de Processo Civil Brasileiro, obra prima de técnica e cultura jurídicas, transformado, posteriormente, em projeto.

Organizou ainda, em abril de 1965, na cidade de Campos de Jordão, o segundo Congresso de Direito Processual; reunindo oitenta professôres brasileiros, pôs em debate o ante-projeto recém elaborado.

Como catedrático, publicou os seguintes trabalhos doutrinários e pareceres:

Do Juizo Arbitral, na Revista da Faculdade de Direito, v. .55, 1960, p. 73 e segs.

$A$ Crise do Supremo Tribunal Federal, na Revista da Faculdade de Direito, v. 55, 1960, p. 327/372.

"Juicio de Amparo" e Mandado de Segurança, na Revista da Faculdade de Direito, v. 56, 1961, p. 172/231.

Do Ônus da Prova, na Revista da Faculdade de Direito, v. 57, 1962, p. $113 / 140$.

Castro Alves, Evangelista do Direito, na Revista da Faculdade de Direito, v. 59, 1964, p. 196/205.

o Tribunal de Contas no Brasil, na Revista da Faculdade de Direito, v. 62, f. 2,1967, p. $37 / 62$.

Rui e a Questão Social, na Revista da Faculdade de Direito, v. 62, f. 1, 1967, p. 207/240.

Deverá Instituir-se no Brasil a Oposição de Terceiro, in Rev. de Direito Processual civil - S. Paulo, 1960, a. 1, v. 1, p. 82-91. 
Direito Subjetivo e Ação: sistema legal brasileiro; locação; ąção revisional de aluguel; requisitos; ajuizamento inadmissivel na vigência de contrato originário; inteligência do art. 31 , do decreto n. 24.150, de 1934. Despacho saneador: legitimidade "ad causam" decidida sem preclusão; reexame da matéria em primeira instância; admissibilidade. (Parecer) In Rev. dos Tribunais S. Paulo, 1966, a. 55, v. 368, p. 40-47.

Exposição de Motivos do Anteprojeto de Código de Processo Civil in Rev. Forense - Rio de Janeiro - 1964, a. 1961, v. 207, p. 26-42.

Falência: citação da emprêsa na pessoa de quem não é representante legal; nulidade do processo "ab initio"; caracterização do estado de insolvência; tipos de depósito instituídos pelo decreto-lei n. 7.661 para ilidir a quebra; conseqüência do depósito; incompetência do juízo quando o estabelecimento principal da devedora se acha fora da sua jurisdição: conceito de principal estabelecimento; inteligência dos artigos $1,2,4, \mathrm{n}$. IV, 11, § 2. , 7. $^{\circ}$, do dec.-lei 7.661. (Pareeer) - in Rev. dos Tribunais, S. Paulo, 1961 , a. 50 , v. 307 , p. 55-64.

"Impeachment": conceito e finalidade; ordem; natureza jurídica inclusive no direito brasileiro. (Parecer) - in Rev. dos Tribunais, S. Paulo, 1965 , v. 355 , a. 54, p. 42-60.

o Impôsto de Indústrias e Profissões no Município de S. Paúlo - in Rev. dos Tribunais - S. Paulo, 1962, a. 51, v. 322, p. 7-19.

Litisconsórcio Necessário; falta de litisconsortes; nulidade. (Parecer) — in Rev. dos Tribunais - S. Paulo, 1965, a. 54, v. 359, p. 44-55.

Locação: ação revisional de aluguel, estabelecimento comercial, fundamento legal, conceito de prorrogação do contrato, (Parecer) in Rev. dos Tribunais, 1955 , v. $44: 231$, p. 33-41.

Locação: arrendamento de imóvel para exploração de fontes de água mineral nele existentes; natureza jurídica do contrato. Locação; renovatória; carência decretada a final: propositura de reintegração de posse e não de despejo para retomada do imóvel pelo locador; meio processual inidôneo. Despacho saneador: falta de interposição de agravo no auto do processo; inexistência todavia de preclusão relativamente à questão da impropriedade da ação. (Parecer), in Rev. dos Tribunais - S. Paulo, 1961, a. 50, v. 309, p. 63-75.

Locação: renovatória; transação entre locador e locatário; cláusula vedando a propositura de outra revocatória, não obstante o ajuste de nova locação por quatro anos; violação dos artigos 29 e 30 
do decreto n. ${ }^{\circ}$ 24.150. (Parecer), in Rev. dos Tribunais -

S. Paulo, 1965, v. 351, a 53, p. 60-64.

Sociedade por ações: conselho fiscal; natureza. (Parecer), in Rev. dos Tribunais, São Paulo, 1965 , a. 54 , v. 356 , p. $69 / 78$.

\section{A solenidade de posse na função de diretor da Faculdade de Direito.}

Em 1966, integrando a lista tríplice apresentada pela Congregação ao Magnífico Reitor da Universidade, foi S. Excia. indicado para a Diretoria desta Faculdade. sucedendo ao Prof. Dr. Luís Eulalio de Bueno Vidigal.

Na sessão solene da Congregação, realizada no salão nobre a 3 de agôsto de 1966, presidida pelo Prof. Dr. Miguel Reale, diretor em exercício, tomou posse na Função de Diretor para o triênio 1966-69.

Além de grande número de estudantes e convidados que ocuparam literalmente o salão, estiveram presentes ao ato altas personalidades do mundo jurídico e político.

Introduzido no recinto, Prof. Alfredo Buzaid foi saudado pelo representante do Centro Acadêmico XI de Agôsto, Sr. Sérgio Lazarini, com palavras de carinhoso respeito.

Em seguida, tomou a palavra o Prof. Miguel Reale que saudou o novo diretor em nome da Congregação; rememorando o tempo acadêmico de ambos, referiu-se ao caráter severo, do então jovem perquisidor do Direito, e às promessas recíprocas, plenamente cumpridas, de intensa e perene dedicação à cultura e à Pátria.

Após agradecer às saudações recebidas, S. Excia. pronunciou o discurso de posse, que, por seu conteúdo especificamente doutrinário, é publicado na abertura da seccão de Doutrina dêste volume, sob o título: A Missão da Faculdade na Conjuntura Política Atual. 